Perwira Journal of Economics and Business (PJEB)

E-ISSN : 2775-572X

Volume 1 Nomor 2

Agustus 2021

\title{
PENGARUH KEPUASAN KERJA TERHADAP ORGANIZATIONAL CITIZENSHIP BEHAVIOR (OCB) ISLAM
}

\author{
Nur Ahmad Budi Yulianto \\ Politeknik Balekambang Jepara, Indonesia \\ (nurahmadbudiyulianto@yahoo.com)
}

\begin{abstract}
Abstrak
Kesuksesan sebuah perusahaan ditentukan oleh pegawainya. Karena pegawai merupakan faktor yang sangat penting untuk mencapai tujuan perusahaan. Suksesnya sebuah perusahaan tercapai apabila perusahaan tersebut mempunyai pegawai yang memiliki perilaku in-role dan perilaku extra-role. Perilaku in-role harus dilakukan seorang pegawai agar dalam bekerja sesuai dengan job deskripsi pekerjaan yang diberikan. Sedangkan perilaku extra-role tidak harus dilakukan oleh pegawai namun, apabila dilakukan dapat memberikan manfaat kepada perusahaan. Diantara perilaku extra-role yaitu Organizational Citizenship Behavior (OCB). OCB dapat muncul apabila seorang pegawai mempunyai kepuasan dalam bekerja, baik puas secara lahir maupun secara kepuasan batin. Penelitian ini bertujuan untuk mengetahui pengaruh kepuasan kerja terhadap organizational citizenship behavior (OCB) Islam. Penelitian ini merupakan penelitian kuantitatif explanatory research dengan metode pengambilan sampel sampling jenuh. Lokasi penelitian di BMT Maslahah dengan populasi Sampel sebanyak 46 pegawai dan semuanya menjadi sampel pada penelitian ini. Metode analisis menggunakan SEM-PLS dengan alat analisis menggunakan software WarPLS 3.0. dari hasil penelitian ini dapat disimpulkan bahwa kepuasan kerja berpengaruh terhadap OCB Islam.
\end{abstract}

Keyword: Organizational Citizenship Behavior, kepuasan kerja, OCB, OCB Islam

\section{Pendahuluan}

Kesuksesan sebuah perusahaan ditentukan oleh pegawainya. Karena pegawai merupakan faktor yang sangat penting untuk mencapai tujuan perusahaan. Suksesnya sebuah perusahaan tercapai apabila perusahaan tersebut mempunyai pegawai yang memiliki perilaku in-role (perilaku yang sesuai dengan job description kerja) dan perilaku extra-role (perilaku yang melebihi job description perusahaan) atau yang dikenal dengan OCB (organizational citizenship behavior) (Sloat, 1999).

OCB merupakan perilaku sukarela untuk melakukan sesuatu yang tidak berkaitan dengan sistem reward dan mampu meningkatkan efektifitas perusahaan (Organ,
1997). OCB menjadikan semua pegawai perusahaan siap bekerja sama dengan seluruh elemen perusahaan utuk mencapai tujuan bersama (Podsakoff, et al., 2000; Kim, 2006; Harper, 2015).

Dalam Islam OCB merupakan manifestasi dari perilaku extra-role pegawai yang mencerminkan kesadaran diri seorang muslim yang bekerja disebuah perusahaan (Nurdiana, 2012). Dalam pandangan islam bekerja tidak hanya melakukan pekerjaan secara sukarela sesuai job deskripsi saja tetapi lebih dari itu adalah untuk mempermudah perusahaan mencapai tujuannya dengan melakukan kegiatan yang bermanfaat dan mencegah organisasi dari kerugian (wibowo, et al., 2013). OCB Islam identik dengan perilaku 
ikhlas bekerja, artinya pegawai yang mempunyai OCB akan bekerja semaksimal mungkin kepada perusahaan dengan tujuan ibadah dan mencari ridho Allah (Nurdiana, 2011). Pada penelitian ini OCB yang dipakai dalam penelitian adalah OCB islam, karena konsep OCB Islam dinilai sangat relevan dengan obyek penelitian yaitu pegawai BMT Maslahah Sidogiri.

Organ menyatakan bahwa OCB mempunyai lima dimensi yaitu. Conscientiousness. Altruisme, Civic, Sportmanship, Courtesy. Selain itu dalam penelitian Podsakoff, et al. (2009) dan Bolino dan Kelemen (2018) dimensi OCB di atas dikembangkan menjadi tujuh, yaitu ditambah peacekeeping dan cheerleading. Berbeda dengan pendapat Diana (2012), bahwa OCB mempunyai 4 dimensi yaitu: At-ta'awun, Sportif, Courtesy dan civic virtue. Sedangkan Wibowo, et al. (2013) mengatakan bahwa OCB mempunyai empat dimensi yaitu, ta'aruf, Tafahum, Ta'awun, Tafakul.

OCB dapat mempengaruhi efektifitas organisasi karena beberapa alasan. Pertama, OCB dapat meningkatkan produktivitas. Kedua, OCB dapat meningkatkan produktivitas manajerial. Ketiga, OCB dapat membantu efisiensi penggunaan sumberdaya secara produktif. Keempat, OCB menurunkan kebutuhan pemeliharaan pegawai. Kelima, OCB meningkatkan efektivitas anggota tim. Keenam, OCB dapat meningkatkan kemampuan organisasi untuk mendapatkan dan mempertahankan SDM yang handal. Ketujuh, OCB dapat menstabilkan kinerja organisasi. Kedelapan, OCB dapat meningkatkan kemampuan adaptasi terhadap perubahan lingkungan (Podsakof, et al, 2000).

Pada thn 1983 Organ mengatakan bahwa yang mempengaruhi OCB adalah kepuasan kerja. Dilanjutkan pada thn 1990an, peneliti masih menitik beratkan pada kepuasan kerja sebagai leading predictor dari OCB (Podsakof, 2009; King, 2002; Nurdiana 2011).
Penelitian tentang hubungan kepuasan kerja terhadap OCB telah banyak dilakukan, diantaranya penelitian yang dilakukan oleh Cun (2012) mengatakan bahwa kepuasan kerja berpengaruh terhadap OCB. Selanjutnya penelitian yang dilakukan oleh Yoon dan Jung (2015) mengatakan juga bahwa kepuasan kerja berpengaruh terhadap OCB (Hakim dkk, 2017; Harnoto dan Hidayah 2018; Singh dan Singh 2019; Sobihah dan Alsheikh, 2019; Torlak, Dkk, 2020).

\section{METODE}

Penelitian ini merupakan penelitian kuantitatif dengan menggunakan metode pendekatan explanatory research. Populasi penelitian ini diambil dari semua pegawai BMT Maslahah Sidogiri berjumlah 46 pegawai. Metode pengambilan sampling menggunakan metode sampling jenuh maka yang menjadi sampel pada penelitian ini adalah seluruh pegawai BMT Maslahah sidogiri cabang Pasuruan. Kuisioner yang disebar 46 kuisioner, namun yang terkumpul kembali 40 kuisioner, karena ada beberapa responden yang bertugas diluar kota. Sebelum kuisioner disebar, instrument di uji validitas dan reliabilitas. Validitas pada penelitian diukur dengan menggunakan kriteria output combined loadings dan cross loading, jika nilai pada loading factor lebih dari 0.40 dan nilai $\mathrm{p}$ signifikan kurang dari 0.05 (solihin dan Ratmono, 2013). Reliabilitas ditentukan berdasarkan composite reliability dan cronbach's alpha. Keduanya harus bernilai diatas 0.70 (Solihin dan Ratmono, 2013). Analisis data menggunakan SEM-PLS menggunakan software WARP-PLS 3.0 untuk mengetahui pengaruh langsung kepuasan kerja terhadap OCB Islam.

\section{Hasil}

Karakteristik responden pada penelitian ini menggunakan metode pengambilan sampel sensus jadi semua anggota populasi merupakan sampel penelitian. Sampel penelitian ini berjumlah 46. Pada penelitian ini karakteristik 
responden dilihat berdasarkan jenis kelamin, umur, pendidikan dan lama bekerja. Karakteristik responden dapat dilihat pada Tabel 1.

Tabel 1. Distribusi Responden berdasarkan usia, pendidikan, masa kerja dan gaji

\begin{tabular}{|c|c|c|c|c|c|}
\hline Usia & $\mathrm{F}$ & $\%$ & Masa Kerja & $\mathrm{F}$ & $\%$ \\
\hline$<20$ Thn & 0 & 0 & 0-3 Thn & 10 & 25 \\
\hline 20-30 Thn & 34 & 85 & 4-6 Thn & 13 & 32.5 \\
\hline 31-40 Thn & 5 & 12.5 & 7-9 Thn & 6 & 15 \\
\hline$>40$ thn & 1 & 2.5 & $>10$ Thn & 11 & 27.5 \\
\hline Jumlah & 40 & 100 & Jumlah & 40 & 100 \\
\hline Pendidikan & $\mathrm{F}$ & $\%$ & Gaji Bulanan & $\mathrm{F}$ & $\%$ \\
\hline SD & 6 & 15 & $<$ Rp. 500.000 & 0 & 0 \\
\hline SMP & 11 & 27.5 & $\begin{array}{l}\text { Rp. } 500.000- \\
1.000 .000\end{array}$ & 0 & 0 \\
\hline SMA & 18 & 45 & $\begin{array}{l}\text { Rp.1.000.000- } \\
1.500 .000\end{array}$ & 6 & 15 \\
\hline Universitas & 5 & 12.5 & $\begin{array}{l}\text { Rp.1.500.000- } \\
2.000 .000\end{array}$ & 21 & 52.5 \\
\hline Jumlah & 40 & 100 & $>$ Rp. 2.000 .000 & 13 & 32.5 \\
\hline & & & Jumlah & 40 & 100 \\
\hline
\end{tabular}

Sumber: Data Primer diolah, 2021

\section{Hasil analisis deskriptif Variabel Kepuasan Kerja}

Respon jawaban atas variabel kepuasan kerja disajikan pada tabel 2. Hasil tersebut menunjukkan nilai kepuasan kerja memiliki nilai 4.47. nilai ini berada diantara 4 (tinggi) dan 5 (sangat tinggi). Berarti, dari hasil tersebut dapat dikatakan bahwa setiap pegawai BMT Maslahah memiliki kepuasan kerja yang tinggi. Secara keseluruhan, indikator kepuasan terhadap rekan kerja merupakan indikator dengan nilai tertinggi yaitu 4,57. Indikator dengan nilai paling rendah terletak pada indikator kepuasan terhadap pekerjaan itu sendiri. Artinya pembagian kerja belum sesuai dengan minat kerja pegawai BMT Maslahah.

Tabel 2. Skor rata-rata variabel kepuasan kerja

\begin{tabular}{|l|l|}
\hline Indikator & $\begin{array}{l}\text { Rata- } \\
\text { rata }\end{array}$ \\
\hline $\begin{array}{l}\text { Kepuasan terhadap sistem } \\
\text { pembayaran }\end{array}$ & 4.45 \\
\hline Kepuasan terhadap promosi & 4.47 \\
\hline
\end{tabular}

\begin{tabular}{|l|l|}
\hline Kepuasan terhadap rekan kerja & 4.57 \\
\hline Kepuasan terhadap supervisor & 4.49 \\
\hline $\begin{array}{l}\text { Kepuasan terhadap pekerjaan itu } \\
\text { sendiri }\end{array}$ & 4.40 \\
\hline Rata-rata Variabel Kepuasan Kerja & 4.47 \\
\hline
\end{tabular}

Sumber: Data primer diolah, 2021

\section{Variabel OCB Islam}

Respon jawaban atas variabel OCB islam disajikan pada tabel 3. Hasil tersebut menunjukkan nilai OCB islam memiliki nilai 4.50 yang berarti pegawai BMT maslahah memiliki OCB Islam yang tinggi dalam bekerja. Hasil tersebut juga menunjukkan bahwa pegawai BMT Maslahah saling mengenal dan memahami rekan kerja beserta organisasinya sehingga menimbulkan rasa ingin saling membantu bahkan rela berkorban demi organisasi secara ikhlas. Indikator ikhlasmemiliki nilai rata-rata tertinggi 4.62 dan nilai terendah berada pada indikator tafahum yaitu 4.35.

Tabel 3. Nilai rata-rata variabel OCB Islam

\begin{tabular}{|l|l|}
\hline Indikator & Rata-rata \\
\hline Ta'aruf (saling mengenal) & 4.44 \\
\hline Tafahum (saling memahami) & 4.35 \\
\hline Ta'awun (saling menolong) & 4.54 \\
\hline Tafakul & 4.56 \\
\hline Ikhlas & 4.62 \\
\hline Rata-rata variabel OCB Islam & 4.50 \\
\hline
\end{tabular}

Sumber: Data primer diolah, 2021

Hal ini menunjukkan bahwa pegawai BMT Maslahah ikhlas bekerja, rela berkorban demi kemajuan orgnisasi dibuktikan dengan mau saling tolong menolong dan saling mengenal satu sama lain namun belum tumbuh rasa saling memahami dalam menyelesaikan pekerjaan.

\section{Uji Validitas}

Pengujian validitas menggunakan software Warp PLS 3.0 dikatakan valid apabila outer loading mempunyai nilai anatar 0.400.70 dan nilai $\mathrm{p}$ value lebih kecil dari 0.05 disetiap masing item pertanyaan secara keseluruhan (Solihin dan Ratmono, 2013). Untuk lebih jelasnya dapat dilihat pada tabel 4. 
Berdasarkan Tabel 4 dapat dilihat bahwa outer loading dan nilai $\mathrm{p}$ lebih kecil $0.05(<0.05)$ yang berarti semua indikator dikatakan valid.

Tabel 4. Nilai Uji Validitas

\begin{tabular}{|c|c|c|c|c|c|c|c|c|c|}
\hline Variabel & \multicolumn{4}{|c|}{ Uji Validitas } & Variabel & \multicolumn{4}{|c|}{ Uji Validitas } \\
\hline \multirow{11}{*}{$\begin{array}{c}\text { KEPUASAN } \\
\text { KERJA }\end{array}$} & Item & $\begin{array}{c}\text { Outer } \\
\text { Loading }\end{array}$ & $P$ value & status & \multirow{11}{*}{$\begin{array}{l}\text { OCB } \\
\text { ISLAM }\end{array}$} & item & $\begin{array}{c}\text { Outer } \\
\text { Loading }\end{array}$ & $P$ value & status \\
\hline & KK1 & 0,578 & $<0,001$ & VALID & & OCB1 & 0,768 & $<0,001$ & VALID \\
\hline & KK2 & 0,713 & $<0,001$ & VALID & & OCB2 & 0,722 & $<0,001$ & VALID \\
\hline & KK3 & 0,482 & 0,012 & VALID & & OCB3 & 0,661 & $<0,001$ & VALID \\
\hline & KK4 & 0,733 & $<0,001$ & VALID & & OCB4 & 0,611 & $<0,001$ & VALID \\
\hline & KK5 & 0,510 & 0,005 & VALID & & OCB5 & 0,888 & $<0,001$ & VALID \\
\hline & KK6 & 0,735 & $<0,001$ & VALID & & OCB6 & 0,700 & $<0,001$ & VALID \\
\hline & KK7 & 0,762 & $<0,001$ & VALID & & OCB7 & 0,769 & $<0,001$ & VALID \\
\hline & KK8 & 0,711 & $<0,001$ & VALID & & OCB8 & 0,656 & $<0,001$ & VALID \\
\hline & KK9 & 0,428 & 0,010 & VALID & & OCB9 & 0,527 & $<0,004$ & VALID \\
\hline & KK10 & 0,595 & $<0,001$ & VALID & & OCB10 & 0,718 & $<0,001$ & VALID \\
\hline
\end{tabular}

Sumber: Data primer diolah, 2021

\section{Uji Reliabilitas}

Uji reliabilitas adalah pengujian yang digunakan untuk mengetahui sejauh mana jawaban seseorang konsisten atau stabil dari waktu ke waktu. Teknik pengujian reliabilitas pada software WarpPLS 3.0 adalah dengan menggunakan nilai Cronbach's Alpha dan Composite Reliable. Kriteria pengambilan keputusannya adalah apabila nilai Cronbach's Alpha dan Composite Reliable lebih besar dari 0,70 maka variabel tersebut sudah reliabel (Solihin dan Ratmono, 2013).Untuk lebih jelasnya disajikan dalam tabel 5 .

Tabel 5. Hasil Uji Reliabilitas

\begin{tabular}{|l|l|l|l|}
\hline \multirow{2}{*}{ Variabel } & \multicolumn{3}{|c|}{ Uji reliabilitas } \\
\cline { 2 - 4 } & $\begin{array}{l}\text { Cronbach' } \\
\text { s Alpha }\end{array}$ & $\begin{array}{l}\text { Composit } \\
\text { e Reliable }\end{array}$ & $\begin{array}{l}\text { Keteranga } \\
\mathrm{n}\end{array}$ \\
\hline $\begin{array}{l}\text { Kepuasa } \\
\text { n Kerja }\end{array}$ & 0,829 & 0,867 & Reliabel \\
\hline $\begin{array}{l}\text { OCB } \\
\text { Islam }\end{array}$ & 0,887 & 0,909 & reliabel \\
\hline
\end{tabular}

\section{Hasil Pengujian Hipotesis}

Analisis data yang digunakan untuk melakukan pengujian hipotesis dalam penelitian ini adalah analisis SEM-PLS dengan software WarpPLS 3.0. Kelebihan program WarpPLS 3.0 adalah dapat mengidentifikasi hubungan nonlinier dan mengoreksi nilai koefisien jalur berdasarkan hubungan tersebut.
Berikut hasil analisis SEM-PLS dengan menggunakan program WarpPLS 3.0 untuk menguji hipotesis yang telah ditetapkan.

\section{Indikator model fit}

Indikator model fit berfungsi membandingkan model terbaik dari berbagai model yang berbeda, diantaranya average $R$ squared (ARS), average path coefficient (APC) dan average variance inflation factor (AVIF). Nilai $\mathrm{p}$ untuk APC dan ARS harus lebih kecil dari 0.05, sedangkan AVIF sebagai indikator multikolinearitas harus lebih kecil dari 5 . Indikator model fit disajikan pada Tabel 6. Tabel 6 menunjukkan bahwa kriteria goodness offit model telah terpenuhi karena nilai $\mathrm{p}$ dari APC kurang dari 0.05 dan AVIF kurang dari 5, walaupun nilai ARS lebih dari 0,05.

Tabel 6. Model Fit Indices and P-Value

\begin{tabular}{|l|l|l|}
\hline & $\begin{array}{l}\text { Model Fit } \\
\text { Indices }\end{array}$ & $\mathrm{P}$ Value \\
\hline $\begin{array}{l}\text { APC (Average Path } \\
\text { Coefficient) }\end{array}$ & 0,477 & $\mathrm{P}<0,001$ \\
\hline $\begin{array}{l}\text { ARS (Average R } \\
\text { Squared) }\end{array}$ & 0,476 & $\mathrm{P}<0,001$ \\
\hline $\begin{array}{l}\text { AVIF (Average } \\
\text { Varience Inflation } \\
\text { Factor) }\end{array}$ & 1,327 & $<5,00$ \\
\hline
\end{tabular}

Sumber: Data primer diolah, 2021 


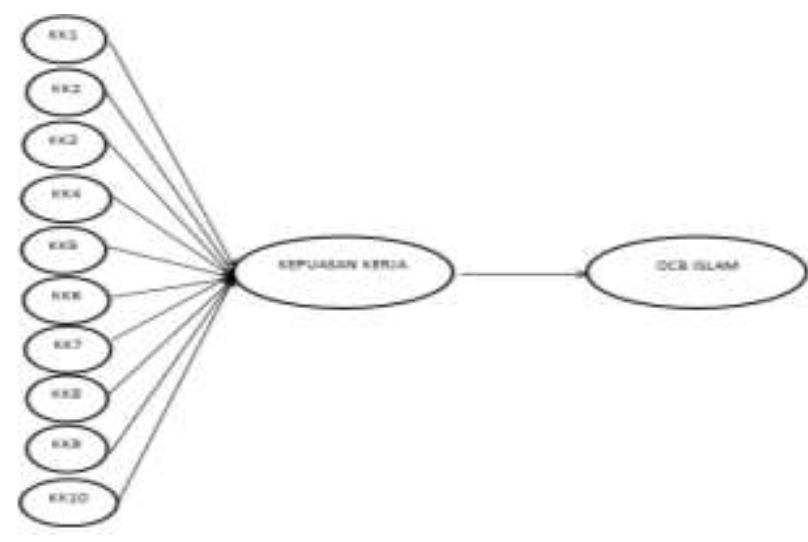

Sumber: Data Primer diolah, 2021

\section{PEMBAHASAN}

Hipotesis penelitian ini menyatakan bahwa kepuasan kerja berpengaruh terhadap OCB Islam. Artinya, bila kepuasan kerja yang dimiliki pegawai semakin meningkat menyebabkan OCB Islam pegawai juga meningkat. Secara empiris, hasil penelitian ini mendukung penelitian yang dilakukan oleh Singh (2018), (Faizal et al., 2019), Obedgiu, et al (2020) dan Torlak (2021) yang memiliki hasil bahwa kepuasan kerja berpengaruh terhadap OCB. Hal tersebut terjadi karena, gaji yang diberikan oleh Manajemen BMT Maslahah kepada pegawai sudah sesuai dengan harapan pegawai, sehingga kebutuhan pegawai terpenuhi. Setelah kepuasan secara lahiriah yaitu kepuasan secara finansial terpenuhi, pegawai BMT maslahah juga mampu memperoleh kepuasan secara batin yang berupa ketenangan dalam hidup. Karena mereka meyakini bahwa bekerja merupakan wujud ibadah kepada Allah, sehingga pegawai dalam bekerja berupaya bekerja semaksimal mungkin karena mereka merasa diawasi langsung oleh Allah. Seperti yang diterangkan dalam hadits Arbain Nawawiyah yang artinya: "Jibril berkata: berilah informasi kepadaku tentang ihsan. Nabi menjawab: hendaklah kamu beribadah kepada Allah, seakan-akan kamu melihat Nya langsung, kalaupun engkau tidak melihatnya, sesungguhnya Allah maha melihatmu (H.R. Muslim)."

Menurut Diana (2012) Perilaku OCB dalam islam identik dengan sikap ikhlas, yakni beribadah dan bekerja semata-mata karena Allah bukan karena ingin dipuji atau ingin mendapatkan imbalan materi. Demikianl halnya penelitian dari (Sulaeman, 2016) bahwa pegawai dengan sikap ikhlas dapat menghasilkan kinerja yang baik. Hal ini diterangkan dalam Al-qur'an surat An-nisa' ayat 125 yang artinya:

"Dan siapakah yang lebih baik agamanya daripada orang yang ikhlas menyerahkan dirinya kepada Allah, sedang diapun mengerjakan kebaikan, dan dia mengikuti agama Ibrahim yang lurus? Dan Allah mengambil Ibrahim menjadi kekasihnya."

Berdasarkan keterangan ayat diatas pekerja yang ikhlas memiliki ciri-ciri selalu memberi lebih dari yang diminta darinya dan bekerja tanpa pamrih dan selalu menjaga hubungan baik sesama rekan kerja ataupun orang lain diluar kerja.

\section{KESIMPULAN}

Dari hasil penelitian ini dapat diketahui bahwa meningkatnya kepuasan kerja pegawai menyebabkan OCB islam yang dimiliki pegawai juga meningkat. OCB Islam identik dengan sifat ikhlas bekerja dengan niat beribadah karena Allah selain untuk mencari nafkah di dunia.

\section{DAFTAR PUSTAKA}

Alquddus Al-qur'an Terjemahan. 2021. Penerbit Menara Kudus: Kudus.

Alsheikh, Ghaith and Sobihah, Mutia Abd Alhlim. 2019. Effect of Behavioral Variables on Organizational Citizenship Behavior (OCB), with Job Satisfaction as Moderating among Jordania Five Star Hotels: A Pilot Study. International Journal Ethics and Sistems. https://www.emerald.com/insight/content/ doi/10.1108/IJOES-01-20190001/full/html . 
Cun, Xiaogang. 2012. Public service motivation and job satisfaction, organizational citizenship behavior: an empirical study based on the sample of employees in Guangzhou public sectors. Chinese management studies, Volume 6, Number 2, 2012, pp. 330-340 (11). https://doi.org/10.1108/175061412112367 58.

Faizal, R., Sulaeman, M., \& Yulizar, I. (2019). Pengaruh Budaya, Motivasi Kerja Dan Kompetensi Terhadap Kinerja Karyawan. EBA Journal: Journal Economics, Bussines and Accounting, 5(1), 11-21. https://doi.org/10.32492/eba.v5i1.706

Sulaeman, M. (2016). Pengaruh Penerapan Nilai-Nilai Islam Dan Komitmen Terhadap Etos Kerja Dan Dampaknya Kepada Kualitas Sumber Daya Manusia Di Lingkungan Pemerintah Kabupaten Tasikmalaya. Jurnal Ekonomi \& Studi Pembangunan, 17(2). https://doi.org/10.18196/jesp.17.2.3788

Harnoto, Harnoto and Hidayah, Siti. 2018. Role of organizational citizenship behavior $(O C B)$, perception of justice and job satisfaction on employee performance. Jurnal Dinamika Manajemen (JDM) Vol. 9, No. 2 (2018).

Harper, Pamelaa, J. 2015. Exploring forms of organizational citizenship behaviors (OCB): antecedents and outcomes. Journal of Management and Marketing Research Volume 18- February, 2015.

Harvey, J., Bolino, M.C. and Kelemen, T.K. (2018). Organizational Citizenship Behavior in the 21st Century: How Might Going the Extra Mile Look Different at the Start of the New Millennium. Buckley, M.R., Wheeler, A.R. and Halbesleben, J.R.B. (Ed.) Research in Personnel and Human Resources Management (Research in Personnel and Human Resources Management, Vol. 36), Emerald Publishing Limited, Bingley, pp. 51-110.
https://doi.org/10.1108/S0742-

730120180000036002.

Hasan, Farid Nu'man. 2021. Syarah Hadits Arba'in An-Nawawi. Gramedia: Jakarta.

Indarti, Sri; Solimun; Fernandes, Adji Achmad Rinaldo and Hakim, Wardhani. 2017. The effect of $O C B$ in relationship between personality, organizational commitment and job satisfaction on performance. Journal of management development Vol. 36 No. 10, pp 1283-1293. https://doi.org/10.1108/JMD-11-20160250.

Jung, H.S., and Yoon, H.H. 2015. The impact of employees' positive psychological Capital on Job Satisfaction and Organizational Citizenship Behaviors in the Hotel. International Journal of Contemporary Hospitality Management, 27(6), 1135-1156.

Kim, Sangmook. 2006. Public Service Motivation And Organizational Citizenship Behavior In Korea. International Journal of Manpower Vol. 27 No. 8, 2006 pp. 722-740.

Murphy, Gregory; Athanasou, James and King, Neville. 2002. Job Satisfaction among Organizational citizenship behavior: A study of Australian Human-service Professionals. Journal of managerial psychology, vol. 17 no. 4, pp. 287-297. https://doi.org/10.1108/026839402104280 92.

Diana, Ilfi Nur. 2012. OCB dalam Islam. Jurnal Ilmu Ekonomi dan Sosial, Jilid 1, Nomor 2, November 2012, hlm.141- 148.

Obedgiu, Vincent; bagire, Vincent; mafabi, Samuel. 2017. Examination of organizational commitment and organizational citizenship behavior among local government civil servants in Uganda. Journal of management development 36(1):0-0. DOI:10.1108/JMD-12-20160279 . 
Organ, D.W. 1997. Organizational Citizenship Behavior: It's Construct Clean-Up Time. Human Performance, 10(2), 85-97.

Podsakof, Philip M., MacKenzie, Scott, B., Paine, Julie Beth., Bachrach, Daniel, G. 2000. OCB: Critical Review of the Theoritical and Empirical Literature and Suggestions for Future Research. Journal of Management 2000 volume 26 No. 3.

Podsakoff, N. P., Whiting, S. W., Podsakoff, P. M., \& Blume, B. D. (2009). Individual and Organizational-Level Consequences of Organizational Citizenship Behaviors: a Meta-Analysis. Journal of Applied Psychology, 94(1), 122.

Singh, sanjay Kumar dan Sing, Ajai Pratap. 2018. Interplay of organizational justice, phsycological empowerment, organizational citizenship Behavior, and job satisfaction in the context of circular economy. Emerald publishing limited Vol. 57 No. 4, pp. 937-952. https://doi.org/10.1108/MD-09-20180966.

Sloat; C M, Kim. 1999. Organizational citizenship: Does Your Firm Inspire employees to be "good Citizens"?. Des Plaines Vol 44 Iss. 4 (Apr 1999):20-23.

Solihin, Mahfud dan Ratmono, Dwi. 2013. Analisis SEM-PLS dengan WarpPLS 3.0 untuk Hubungan Nonlinier dalam Penelitian Sosial dan Bisnis. Yogyakarta: Penerbit Andi.

Torlak, nuri Gökhan; Kuzey, Cemil; Dinc, Muhammet Sait dan Budur, Taylan. 2020. Links connecting nurses' planned behavior, burnout, job satisfaction and organizational citizenship behavior. Journal of Workplace Behavioral Health 36(1):77-103

DOI:10.1080/15555240.2020.1862675.

Wibowo, Ugung D.A., Iskandar, Tb. Zulrizka, and Prathama, A. Gimmy. 2013. Organizational Commitment as Mediator of Antecendents of Organizational Citizenship Behavior in Sharia
Organization. International Conference on Economics, Education and Humanities (ICEEH'14) Dec. 10-11, 2014 Bali (Indonesia). 